This is a peer-reviewed, accepted author manuscript of the following research article: Begum, S. R., Kumar, M. S., Pruncu, C. I., Vasumathi, M., \& Harikrishnan, P. (2021). Optimization and fabrication of customized scaffold using additive manufacturing to match the property of human bone. Journal of Materials Engineering and Performance. https://doi.org/10.1007/s11665-020-05449-7

\title{
Optimization and Fabrication of Customized Scaffold Using Additive Manufacturing to Match the Property of Human Bone
}

\author{
S.Rashia Begum ${ }^{1}$, M.Saravana kumar, ${ }^{2}$, , C.I.Pruncu ${ }^{4,}{ }^{5}$, M.Vasumathi ${ }^{1}$, P.Harikrishnan ${ }^{6}$ \\ 1, Department of Mechanical Engineering, College Of Engineering, Anna University, Chennai, Tamilnadu, \\ India. \\ ${ }^{2 *}$ Department of Mechanical Engineering, Mount Zion College of Engineering and Technology, Pudukottai, \\ Tamilnadu, India. \\ ${ }^{3}$ Department of Mechanical Engineering, Sri Sai Ram Institute of Technology, Chennai, Tamilnadu, India. \\ ${ }^{4}$ Design, Manufacturing \& Engineering Management, University of Strathclyde, Glasgow, G1 1XJ, Scotland, \\ UK. \\ ${ }^{5}$ Department of Mechanical Engineering, Imperial College London, Exhibition Rd., SW7 2AZ, London, UK \\ ${ }^{6}$ Department of Meterials and Production Engineering, King Mongkut's University of Technology North \\ Bangkok (KMUTNB), Bangsue, Bankok.
}

\begin{abstract}
Additive manufacturing plays a major role in medical science. One of the applications is the development of bone scaffolds. During scaffold fabrication, obtaining the properties of the polyamide scaffolds to mimic the elastic properties of human subchondral bone is a challenging task. In order to overcome this challenge, the present numerical study validated by experimental routine allows optimizing, fabricating and automating the generation of open-porous polyamide scaffolds. Human subchondral bone has an elastic modulus of 1.15 $\mathrm{GPa}$ and pore size of $800 \mu \mathrm{m}$ which helps for cell in-growth. The design parameters such as strut diameter $(0.6$ to $3 \mathrm{~mm})$ and unit cell size $(1.4$ to $5 \mathrm{~mm})$ were considered for this investigation. The optimized scaffold structure was fabricated using selective laser sintering method, one of the Additive Manufacturing (AM) processes and the structure was validated through uniaxial compression. Experimental test revealed a deviation in structural modulus of about $14 \%, 10 \%$ and $17 \%$ for circular, square and hexagonal cross-section respectively. Optimized unit cell dimensions were found. The preliminary MTT (Methyl Thiazolyl diphenyl- Tetrazolium bromide) assay tests to evaluate the distributions of cells were performed, using in-vitro perfusion culture experiments. It was found that the scaffold structure with square cross section has the maximum percentage of cell viability of $58.33 \%$. A Computer-Aided Design tool was developed using CATIA V5 Visual Basic program for modelling the bone scaffolds with better interconnectivity of unit blocks, porosity and compressive strength. This program facilitates automatic generation of optimized scaffold structure by providing necessary input parameters. The developed CAD tool was efficient enough to model the customized scaffold.
\end{abstract}

Keywords-Rapid prototyping, optimization, Bone Scaffold, Computer Aided Design, Structural Modulus

\section{INTRODUCTION}

Tissue engineering helps to repair and replace the structural tissue, so it has a wide range of medical application. Tissue engineering combines the principles of materials and cell 
transplantation to develop the substitute tissues and promote endogenous regeneration [1]. The idea of tissue engineering represents the making of a scaffold structure that has the suitable physical, chemical, and mechanical properties to enhance cell penetration and tissue development in three dimensions. Additive manufacturing can be used to fabricate open porous scaffolds [2]. By the use of additive manufacturing technique, geometry and sufficient mechanical property required for the bone regeneration can be obtained. Polyamide has sufficient mechanical properties and can be successfully used as implants in clinical application. Young's modulus of poly amide is found to be $2.5 \mathrm{GPa}$ and its Poisson ratio is $0.3[3]$.

However, the bone healing can be affected by the properties of the scaffold. Some of the properties are pore size, pore shape, pore-wall thickness, pore interconnectivity, Surface morphology and surface chemistry to facilitate cell attachment and migration $[4,5,6,7]$. In addition to these properties, scaffold must also exhibit sufficient mechanical stability in load bearing areas [8]. Elastic property of the bone scaffold should match the elastic property of the bone in order to avoid stress shielding. Stress shielding refers to the reduction in bone density (osteopenia) as a result of removal of normal stress from the bone by an implant [9]. This was done by remodelling the bones of the animal or a person with respect to the corresponding loads. Stress shielding results in loosening of bone implant. One of the major limitations of the SLS process lies in fabricating a scaffold with a pore size lesser than its laser spot diameter [10]. The laser beam diameter of the machine used for scaffold fabrication was $0.6 \mathrm{~mm}$ to $0.7 \mathrm{~mm}$. Experimental studies to determine the characteristic of scaffold is time consuming and cost intensive process. Finite element analysis can be utilized to study the mechanical property of the scaffold. This helps in reducing the experimental study, thus time and cost efficient. Scaffold with optimized mechanical properties can be obtained [11, $12,13,14,15]$. The computer aided modelling approach was an effective tool for constructing customized bone scaffold $[16,17,18]$.

Poly(lactic-co-glycolic acid) (PLGA) materials have great potential in clinical applications due to their higher degradability, biocompatibility, excellent mechanical properties, better process ability, and the ability to promote bone regeneration. However, small-scale production and low efficiency of manufacturing are the limitations of PLGA in bone scaffold applications [19]. Cui et al, [20] reported a novel PLGA/HA/PLA-AP/phBMP-4 scaffold with potential for accelerating the repair of large-scale bone defect. It was reported that the addition of phBMP-4 into an electro active bone repair material could enable rapid, efficient, and high-quality healing of large-scale bone defects. Poly(glycolic acid) (PGA) plays a pivotal role among biodegradable polymers due to their strong hydrophilic nature leading to relatively rapid degradation rate immersed in body fluids. PGA incorporated with Hydroxyapatite (HAP)/ poly-L-lactic acid (PLLA) scaffolds exhibit higher rate of degradation and enhances the bioactivity and osteoconductivity of HAP. Shuai et al, [21] investigated on the effect of PLLA/PGA ratio in composite scaffolds fabricated by laser 3D printing technology. They reported that the incorporation of PGA, increased the water uptake capacity and degradation rate thus, increasing the contact area between PLLA and body fluid. In an important work, Shuai et al, [22] investigated on the effect of organically modified montmorillonite (MMT) incorporated in poly ( $\varepsilon$-caprolactone) (PCL) based bone scaffold material. The amine functional silane coupling agent (3-aminopropyl) triethoxysilane is found to produce interlayer locking effect in polymer scaffold to enhance interfacial bonding. As a result, the load bearing capacity and impact properties of the scaffold improved tremendously. In several studies, the bone regeneration in osteonecrosis using 3D scaffolds 
processes was reported. 3D scaffolds accommodate the long-term bone regeneration by controlled biodegradability and biocompatibility. They also enhance the ingrowth of new bone and neo-vascularization by enhancing the porosity [23]. Several studies investigated the impact of pore size on tissue regeneration such as pore size between $0.2 \mathrm{~mm}$ to $0.5 \mathrm{~mm}$ [24, 25], pore size less than $0.2 \mathrm{~mm}$ [26] and also with much larger pore size up to $2.2 \mathrm{~mm}$ [27].

The focus of this research is to optimize the structural modulus of scaffold structure in order to match the elastic property of bone and to auto-generate microstructures (unit block) by means of the newly developed CAD tool. It enables the micro structures to get integrated piecewise and effortlessly combined into a scaffold structure based on their mechanical function.

1. Our study incorporated modelling of various micro structures and performing finite element analysis on them, with the assistance of the CAD tool, to determine their mechanical properties over a range of porosities.

2. After generating the scaffold structure, it was optimized to suit the human bone through interpolation to acquire the preferred mechanical properties and porosities by varying the strut diameter and the size of the unit block.

3. Thus, an optimized scaffold structure with similar characteristics of human bone, was evolved after a series of trials.

4. Standard test samples were fabricated with polyamide by AM process and were subjected to compression test.

5. The mechanical properties of the microstructures, obtained through the analytical process were validated using the experimental results obtained from the compression test.

6. The preliminary MTT (Methyl Thiazolyl diphenyl- Tetrazolium bromide) assay tests to evaluate the distributions of cells were performed, using in-vitro perfusion culture experiments.

7. A Computer-Aided Design tool has been developed using CATIA V5 Visual Basic program for modelling the bone scaffolds with better interconnectivity of unit blocks, porosity and compressive strength

\section{MATERIALS AND METHOD}

In this study, scaffold structure was optimized to match the elastic property of human subchondral bone and a special CAD tool was developed to model the customized bone scaffold. The scaffold structures were fabricated using 3Dfast Srl on a Formiga P100 system $(\mathrm{EOS} \mathrm{GmbH})$ in polyamide EOSINT P/PA2200. In the optimization procedure, unit cell with three different cross sections were chosen for investigation. The range of unit cell size and pore size was selected to characterize the mechanical property of the scaffold. These unit cells were used to develop the scaffold structure, which was optimized to match the elastic property of human subchondral bone. For further application, the validation of the numerical data was done through experimental testing. Finally a CAD tool has been developed in CATIA V5 to automate modelling of scaffold in the shape of human bone using the chosen unit cell.

\subsection{Modelling of scaffold structure}

For this numerical study, unit cells with three different cross sections were developed. Unit cells were cubical wire frame structures, made of wires with circle, square and hexagonal cross sections, and these unit cells were named as unit cell $\mathrm{A}, \mathrm{B}$ and $\mathrm{C}$ respectively as shown in Figure 1. Generation of the numerical models were performed by using the finite element software package ABAQUS (version 6.13-1, Dassault Systèmes). Scaffolds were generated as linear pattern of one structure, having three unit cells in a row and in each spatial 
direction $\mathrm{X}, \mathrm{Y}$ and $\mathrm{Z}$ thus consisting of 27 unit cells. Figure 2 shows the scaffold structures with stacking of unit cell A, B and C. Pore size of the scaffold structures were calculated based on design parameters i.e. unit cell size and strut diameter.
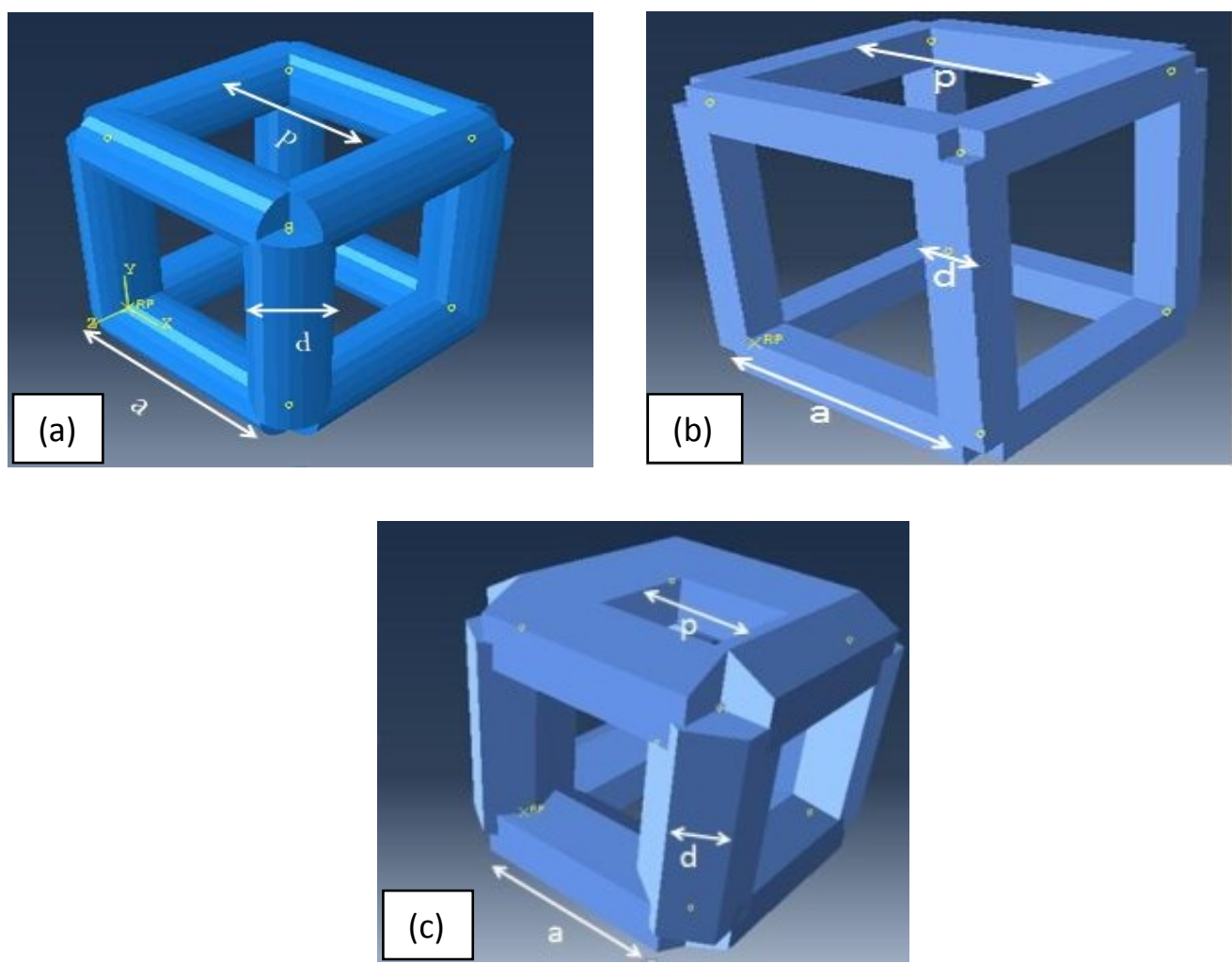

Figure.1. Unit cell (a) A, (b) B and (c) C.
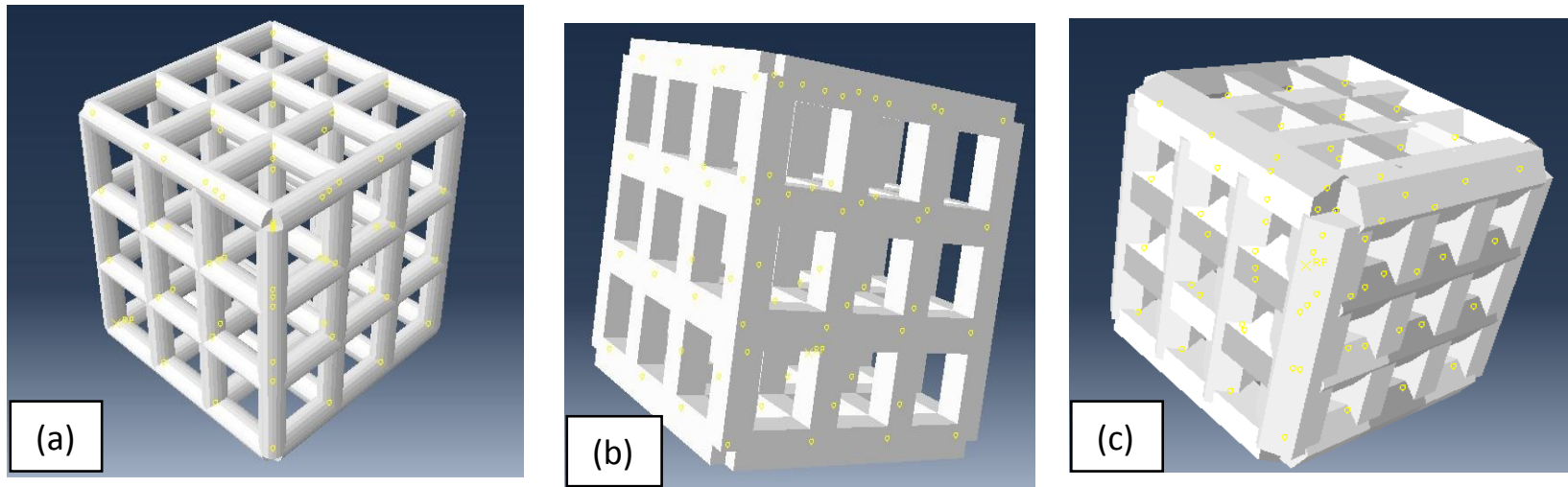

Figure.2. Stacking of Unit cell (a) A, (b) B, and (c) C.

Pore size for circular and square cross sections.

$$
p=a-d
$$

Pore size for hexagonal cross section

$$
p=a-\frac{2}{\sqrt{3}} d
$$


To characterize the mechanical properties of the scaffold structure, upper and lower limits were selected for strut diameter and unit cell size ranges between $0.6-3 \mathrm{~mm}$ and $1.4-5 \mathrm{~mm}$ respectively. Lower limit of the strut diameter was chosen to achieve better mechanical integrity and the unit cell's upper limit was selected based on the range of interest. Pore size has to be limited within $2.2 \mathrm{~mm}$ for efficient cell in growth [28].

\subsection{Element type and material property}

All scaffold structures have been modelled as fully parameterized model by using finite element software package ABAQUS. Struts have been implemented as structural beams featuring a circular, square and hexagonal cross section. Scaffold structures were meshed with beam element using Timoshenko's theorem with linear interpolation function in order to provide sufficient mechanical behaviour. The material chosen for scaffold manufacturing should be bio compatible in nature. Polyamide is bio compatible in nature. Hence scaffold structure was made of polyamide. Therefore, material properties were modelled as linear elastic and homogeneous with Young's modulus of $1.15 \mathrm{GPa}$ and Poisson's ratio of 0.3.

\subsection{Loading and boundary condition}

The boundaries on the bottom surface of the scaffolds were controlled in the vertical $Y$ direction. Furthermore one edge was constrained in horizontal X-direction and other edge in Z- direction to arrest rigid body motion but allow transverse deformation. Displacement of $10 \%$ of height of the scaffold (depends on size of the unit cell) was applied to edge on the upper surface in vertical downward direction. Figure 3 and Figure 4 shows the application of displacement and fixed boundary condition respectively.

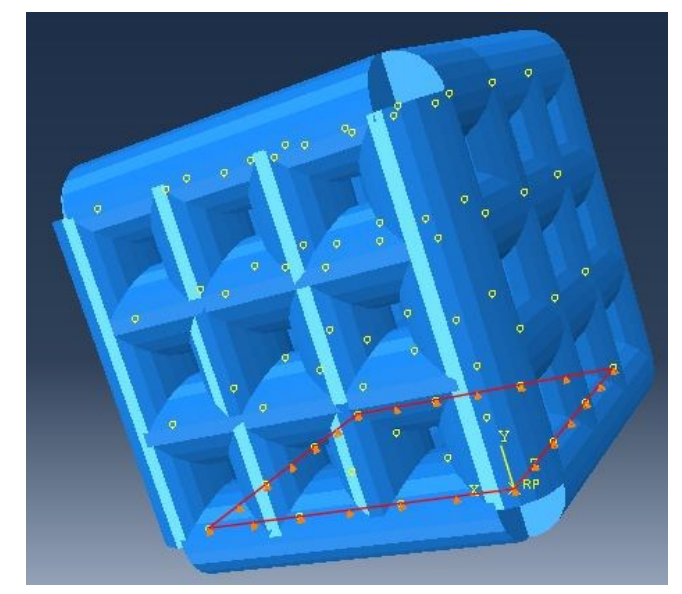

Figure.3. Displacement boundary conditions. 


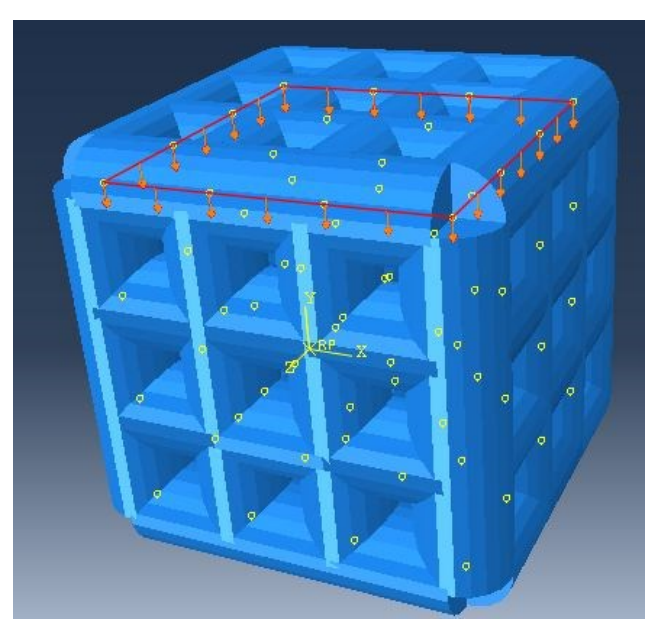

Figure.4. Fixed boundary conditions.

\subsection{Convergence test}

Convergence test is to determine the number of element required per strut to produce an accurate result. A scaffold structure having a unit cell with circular cross section, strut diameter of $0.7 \mathrm{~mm}$, unit cell size of $1.8 \mathrm{~mm}$ and pore size of $1.1 \mathrm{~mm}$ was chosen randomly. It was meshed with $1,5,10,15,20,25,30,35$ and the corresponding reaction force was calculated.

\subsection{Sensitivity analysis}

Sensitivity analysis is to determine mechanical response of the scaffold structure for the variation of the design parameters such as strut diameter, unit cell size and pore size. In this analysis one parameter of the scaffold was kept constant, other parameters were varied from its initial value and the response of the structure was studied. In the first analysis, unit cell size was kept constant and strut diameter was varied by $20 \%$ from initial value up to $100 \%$. In the next analysis strut diameter was kept constant and unit cell size was varied by $20 \%$ from its initial value. Third step of sensitivity analysis was maintaining the pore size constant by increasing the strut diameter and unit cell size simultaneously. A finite element simulation was performed for the given set of parameters.

Structural responses were investigated. The obtained numerical results were used for the calculation of the structural modulus Es of the scaffold using the equation.3 [29].

$$
E_{S}=\frac{F_{r} \times l_{o}}{A \times \Delta l}
$$

$\mathbf{E}_{\mathbf{s}}=$ Structural modulus of the scaffold.

$\mathbf{F}_{\mathbf{r}}=$ Reaction force.

$l_{0}=$ Initial height of the scaffold

(i.e. three times the unit cell size)

$\mathbf{A}=$ Enclosed surface area of the scaffold neglecting the pores

$\Delta l=$ Compression length.

(10\% of initial height of the scaffold) 


\subsection{Optimization}

Design parameters were varied based on the response of the scaffold structure which helps to optimize the structural modulus of the scaffold to $1.15 \mathrm{GPa}$. Considering the mechanical integrity and to maintain the pore size within the specified range, strut diameter was fixed as $0.6 \mathrm{~mm}$ and the design parameters were varied to optimize the scaffold. Initial pore size of 0.8 mm was chosen.

\subsection{Fabrication}

Selective laser sintering method was used to fabricate the scaffold structure. During the fabrication process, the laser beam was used to scan selectively over the powder surface based on the slice data. The laser beam will reach the melting point of the particles which helps to fuse together to create a solid mass. Consecutive layers were built over the previously sintered layers. And new layers of powder are deposited via a roller on top of the previously sintered layer. Figure 5 shows principle of selective laser sintering.

The compression test specimen was fabricated as one inch cube $(25.4 \mathrm{~mm} \times 25.4 \mathrm{~mm} \times 25.4$ $\mathrm{mm}$ ) according to ASTM D695: ISO 604. Figure 6 shows the fabricated scaffolds. Figure.7 shows the SEM image of the pore. It was observed that there is no interlayer differentiation when probed on the exterior face of the part. This indicates complete sintering of the polymer, and good metallurgical bonding between layers, during the fabrication process.

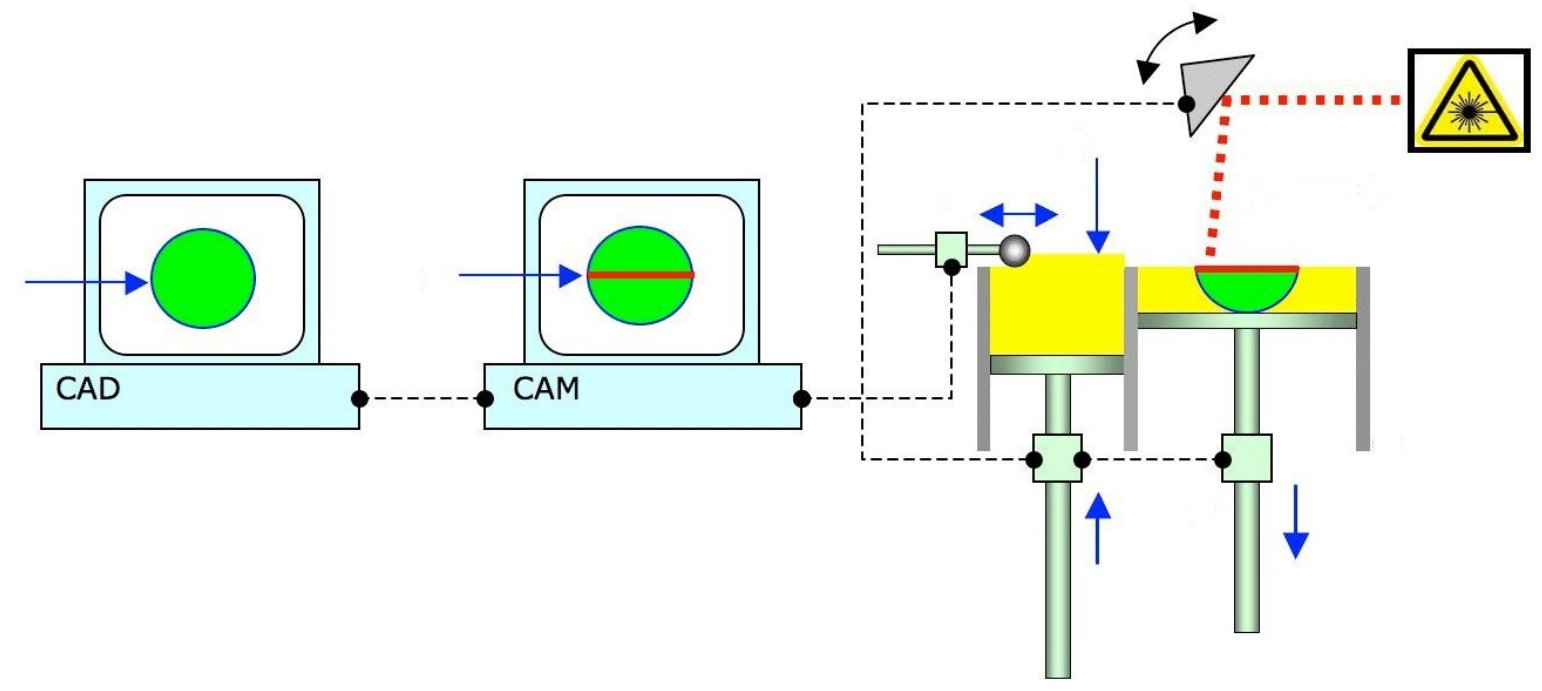

Figure.5.Principle of Selective Laser Sintering.
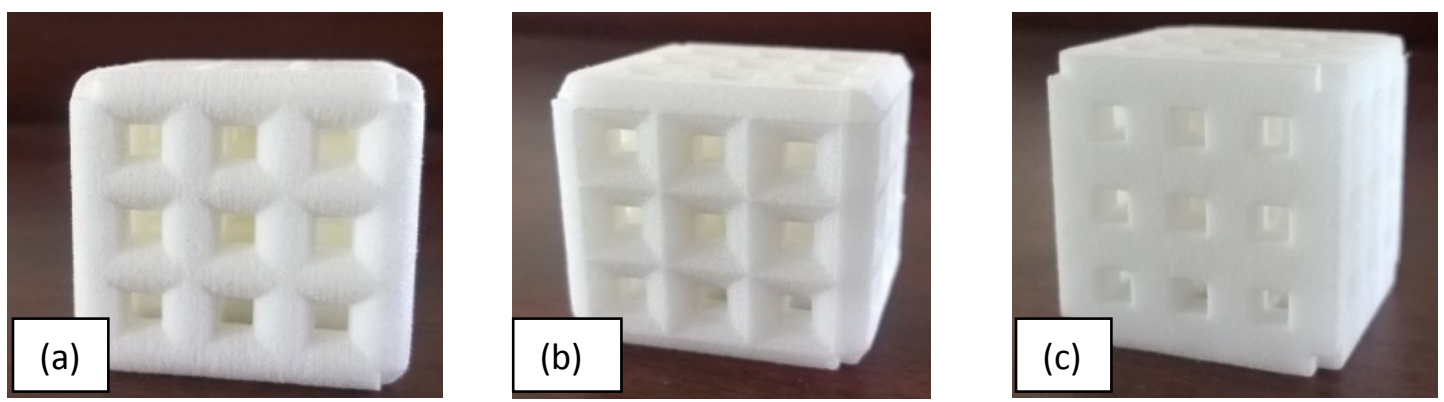

Figure .6.Fabricated Scaffolds (a) Circle (b) Hexagon (c) Square 


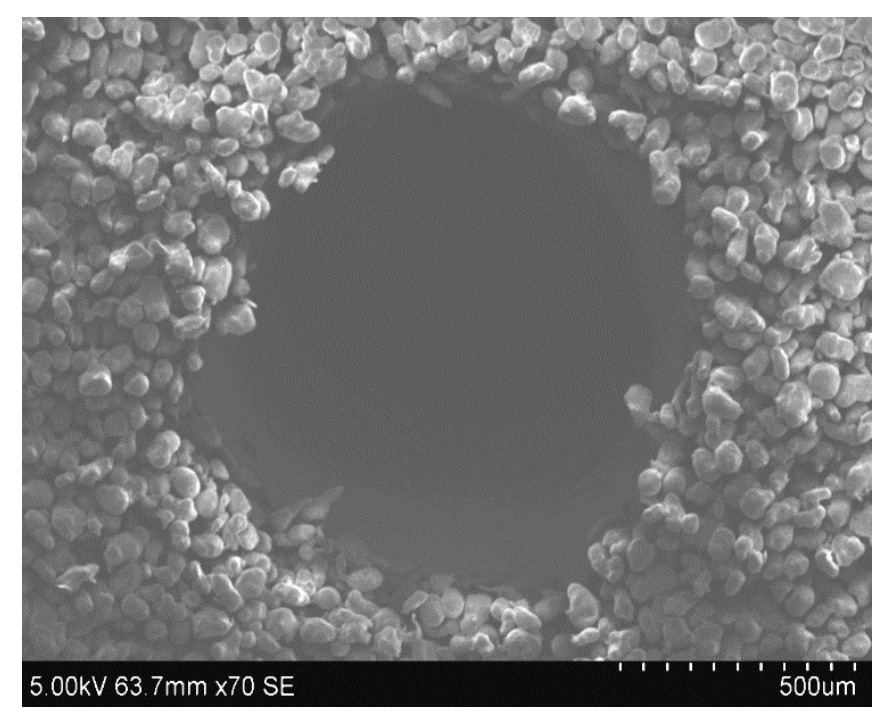

Figure.7 SEM image showing defined circular pore shape

\subsection{Experimental testing}

The compression test specimens were fabricated according to the ASTM D695: ISO 604. Mechanical testing was carried out for all the scaffolds to find their structural modulus. The universal testing machine with a transverse velocity of $2.5 \mathrm{~mm} / \mathrm{s}$ was used to perform axial compression test until mechanical failure. Values of applied load and corresponding displacement were continuously recorded. Compression testing of fabricated scaffold was shown in Figure.8. Once, the compression force was induced in the bone scaffold, plastic deformation will occur. After reaching the yield strength, it will continue to deform until it breaks. But at some point, the scaffold deformation was prolonged until it became flat. In either case maximum stress was evident, providing its ultimate compressive strength values. Figure 9 shows the broken scaffold for various structures.

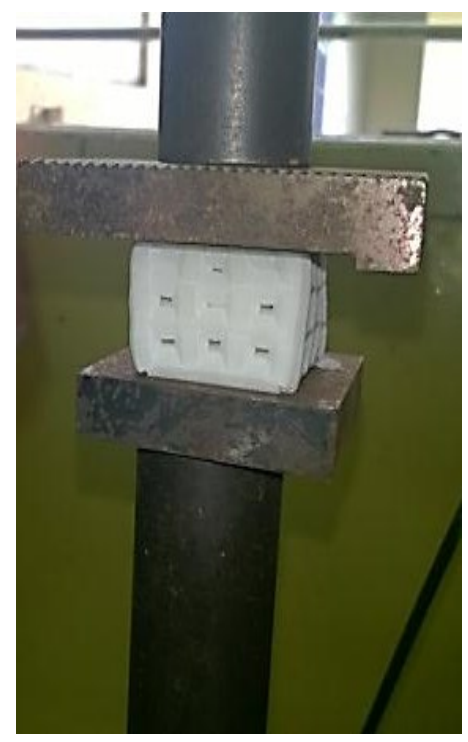

Figure.8. Compression Testing of Scaffold 

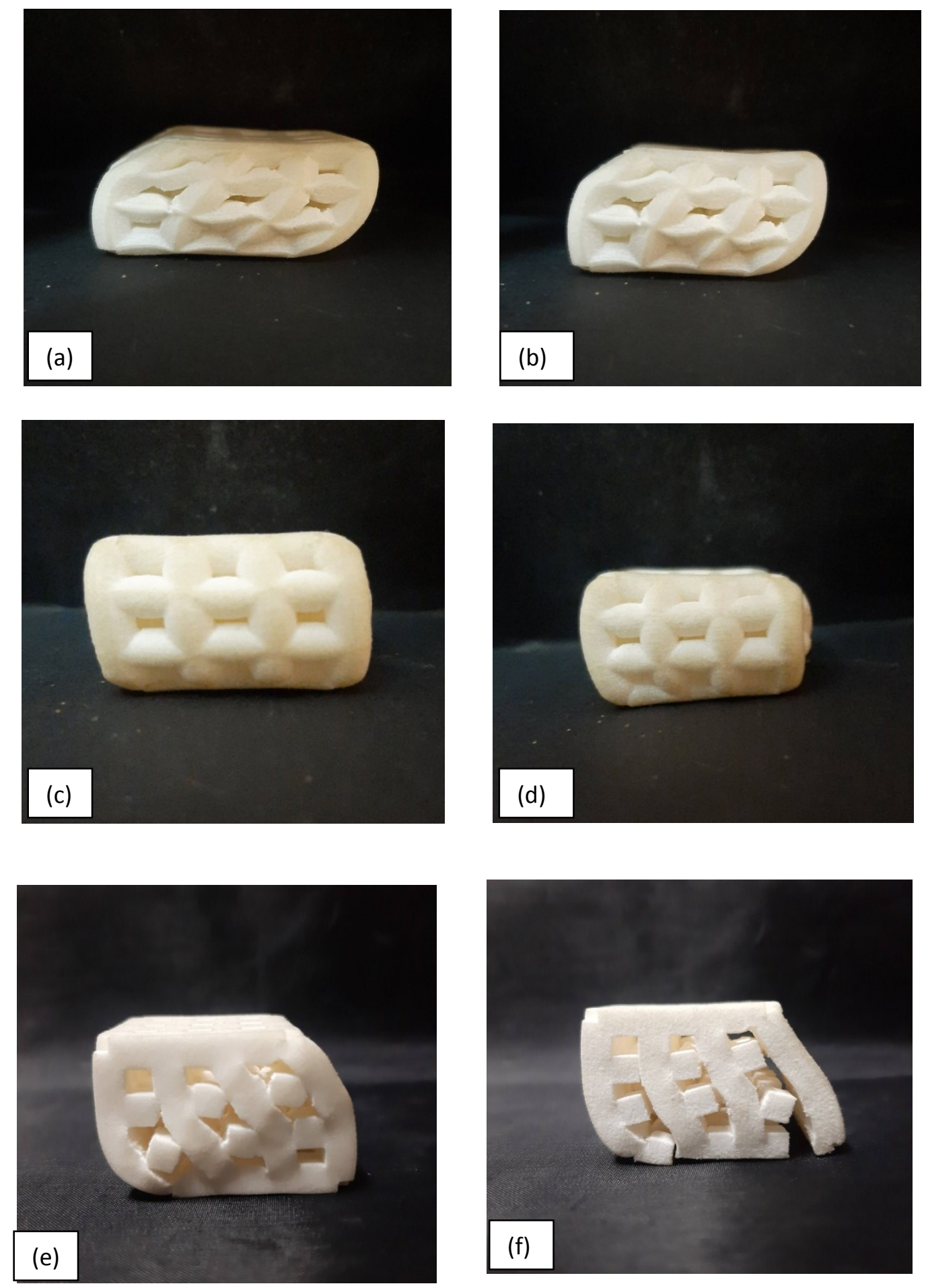

Figure.9. Broken Scaffolds (a), (b) - Hexagonal cross section, (c), (d) - Circular cross section, (e), (f) - Square cross section 


\subsection{In-vitro testing}

Polyamide is biocompatible. The applied heat onto polyamide during the Additive Manufacturing process may produce cytotoxicity on the specimen. The MTT assay test can be used to verify the feasibility of selective laser sintered polyamide as scaffold material to fabricate the scaffold.

The osteoblast cell line (MG-63) was obtained from the National Centre for Cell Science (NCCS), Pune. The cells were maintained in Dulbecco's Modified Eagle Medium (DMEM) supplemented with $10 \% \mathrm{FBS}$, penicillin $(100 \mathrm{U} / \mathrm{ml})$, and streptomycin $(100 \mu \mathrm{g} / \mathrm{ml})$ in a humidified atmosphere of $50 \mu \mathrm{g} / \mathrm{ml} \mathrm{CO} 2$ at $37{ }^{\circ} \mathrm{C}$ [30]. Dulbecco's Modified Eagle Medium (DMEM) was purchased from Hi Media Laboratories. Fetal Bovine Serum (FBS) was purchased from Cistron laboratories. Trypsin, Methyl Thiazolyl diphenyl- Tetrazolium bromide (MTT), and Dimethyl Sulfoxide (DMSO) were purchased from (Sisco research laboratory chemicals, Mumbai). All the other chemicals and reagents were obtained from Sigma Aldrich, Mumbai.

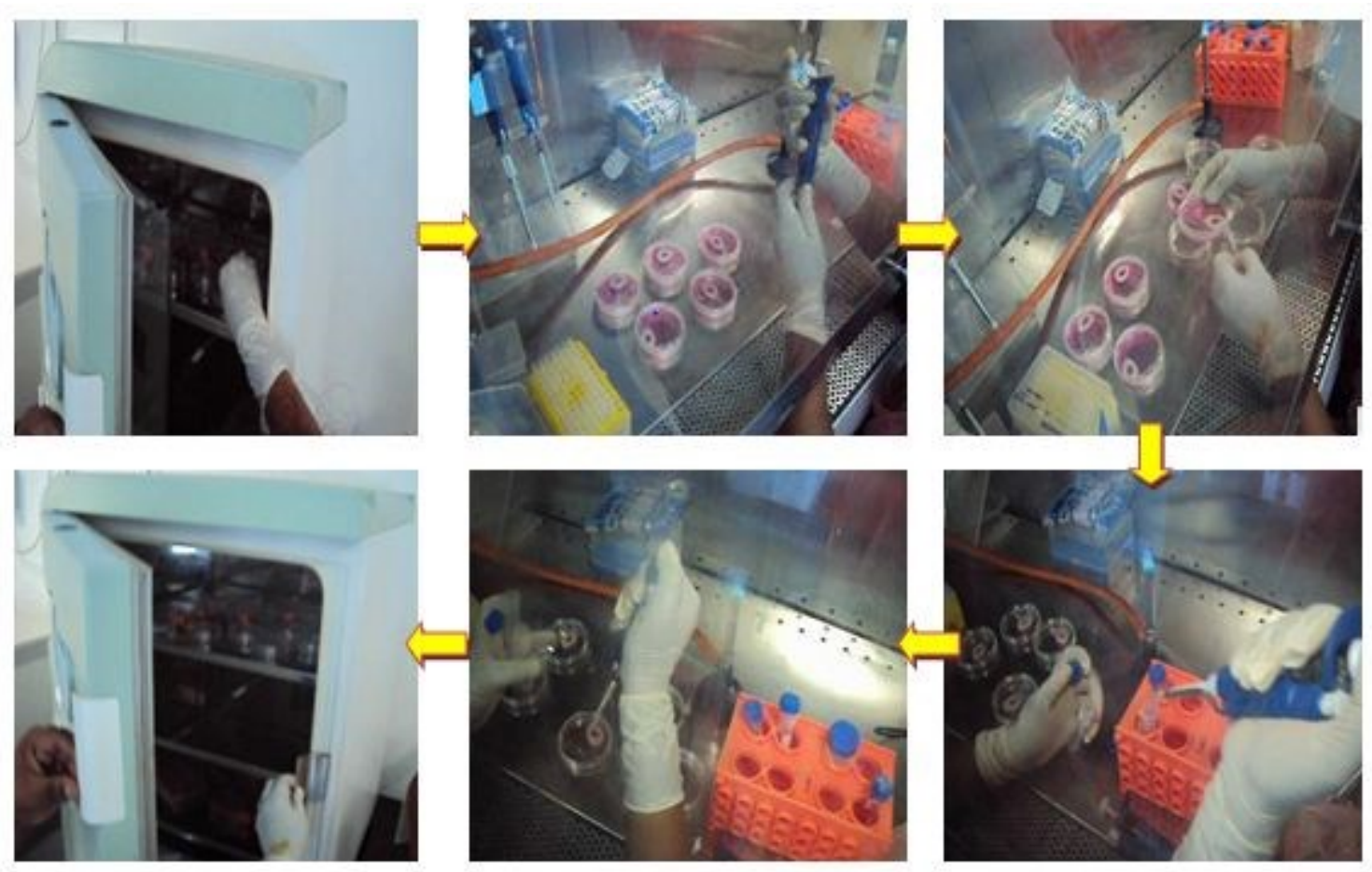

Figure.10 Cell culture procedures

The bone scaffold was used to conduct in-vitro test as shown in Figure 1.

1) The scaffold was autoclaved prior to culturing with cells.

2) The scaffold was washed with $70 \%$ ethanol twice [31], and then rinsed with PBS (phosphate buffered saline).

3) Then the scaffold was transferred carefully with forceps onto a sterile culture plate (60 $\mathrm{mm}$ ) and was conditioned in Dulbecco's Modified Eagle Medium (DMEM) for two hours in $37^{\circ} \mathrm{C}$ incubator (with $5 \% \mathrm{CO}_{2}$ and $95 \%$ humidity). 
A $\mathrm{CO}_{2}$ incubator operates on fairly simple parameters based on three elements: carbon dioxide $\left(\mathrm{CO}_{2}\right)$, temperature and relative humidity $(\mathrm{RH})$. A scientist using a $\mathrm{CO}_{2}$ incubator is trying to reproduce the mammalian environment (in-vivo) outside of its natural state (in vitro). Therefore, the incubator combines three elements that create an environment needed for cells to thrive by establishing a balanced and controlled $\mathrm{pH}$ at 7.2-7.4: stable temperature at $37^{\circ} \mathrm{C}$, high $\mathrm{RH}$ at $95 \%$, and controlled $\mathrm{CO}_{2}$ level at $5 \%$.

4) The medium was then drained off the scaffold, and the concentrated cell suspension $\left(1 \times 10^{6}\right.$ cells $\left./ \mathrm{ml}\right)$ was loaded onto the scaffold, and incubated at $37^{\circ} \mathrm{C}$ in the incubator for two hours.

5) About $3 \mathrm{ml}$ medium and $1 \%$ FBS (Fetal Bovine Serum) [32] was added to the scaffold, and it was incubated for 3-7 days at $37^{\circ} \mathrm{C}$ incubators.

6) After 3 days of incubation of cells on the scaffold, the scaffold with the cells was prepared for cell viability assay - MTT (Methyl Thiazolyl diphenyl- Tetrazolium bromide).

7) The medium from the scaffold was drained and about $3 \mathrm{ml}$ of PBS-Trypsin $(0.25 \%)$ in 2:1 dilution was added to the scaffold and flushed vigorously onto the scaffold, to flush out the attached cells. The flushed PBS-Trypsin was collected in fresh $15 \mathrm{ml}$ Falcon tubes. This washing was repeated twice.

8) The collected PBS-Trypsin was centrifuged at $1500 \mathrm{rpm}$ for 20 minutes, and the pellet formed was carefully resuspended in $200 \mu 1$ of DMEM medium and loaded onto the wells in a 96 well plate.

9) Cells grown in a 6 well plate were also trypsinized and plated in the same 96 well plate. This was used as the positive control (cells not grown on the scaffold). Then, about $10 \mu 1$ of MTT was added into each well, and incubated for 4 hours at $37^{\circ} \mathrm{C}$ in an incubator in the dark

10) After 4 hours the MTT with some PBS was flushed from each well and centrifuged again at $1500 \mathrm{rpm}$ for 10 minutes. The supernatant was removed and the pellet was added in all the wells. $150 \mu \mathrm{L}$ DMSO was added in each well and incubated for 30 minutes in the incubator. Then the colour formed was analysed in an ELISA reader at $595 \mathrm{~nm}$ wavelength.

11) The readings were noted down and analysed.

The absorbance at $570 \mathrm{~nm}$ was measured with a UV- Spectrophotometer, using wells without samples containing cells as blanks. The effect of the samples on the proliferation of MG-63 was expressed as the \% cell viability, using the formula given in Equation 1.

$$
\% \text { cell viability }=\frac{\text { A } 570 \text { of treated cells }}{\text { A } 570 \text { of control cells }} \times 100
$$

\subsection{Development of CAD tool}

Visual Basic program has been developed for automatic generation of bone scaffold with user defined specifications of bone and structures. Working methodology of the program was shown in Figure 11. 


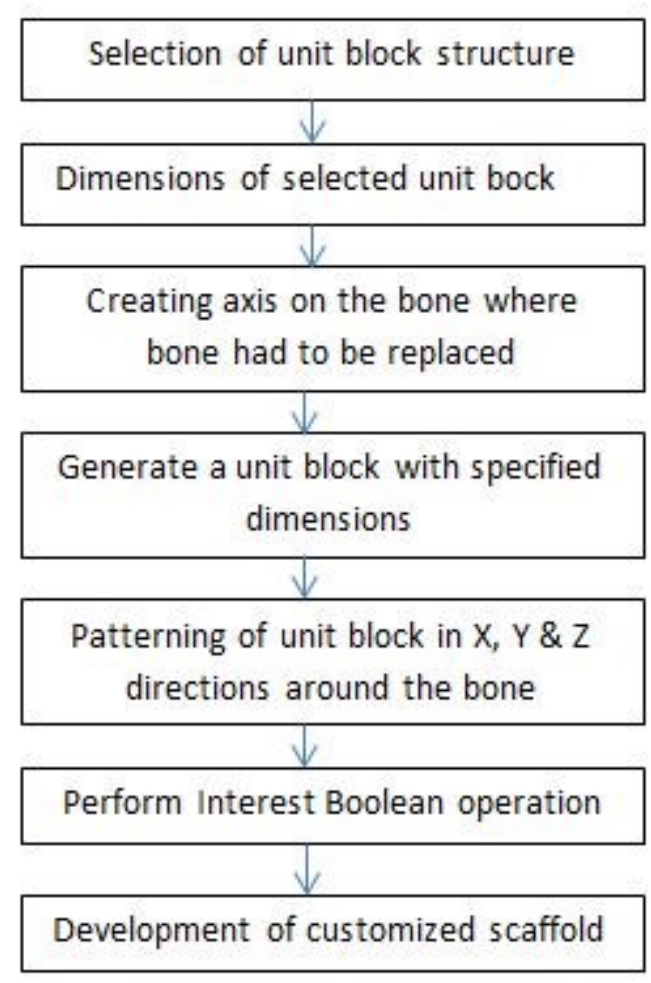

Figure.11. Working Methodology of CAD tool

Three unit cells with different cross sections were developed. Each unit cell has its own design parameters. By providing the design inputs one can change the unit cell size and strut diameter of the cell [33]. A co-ordinate system was created on the surface where scaffold has to replace the bone, followed by the generation of a unit block on the origin [34]. The single unit block generated was patterned in directions orthogonal to each other in and around the bone which has to be replaced [35]. Then Intersect Boolean operation was performed to get the scaffold in the shape of the bone with the specified unit cell structure.

\section{RESULT AND DISCUSSION}

\subsection{Finite element optimization}

The variation of design parameters, unit cell size and the strut diameter showed similar influence in the structural modulus of all three investigated scaffold. It shows the response of the scaffold structure with circular cross section for the variation of design parameters. For the initial unit cell size and strut diameter the scaffold structure with circular cross section revealed a structural modulus of $0.417 \mathrm{GPa}$. The result of sensitivity analysis is shown in the Figures 12, 13 and 14. 


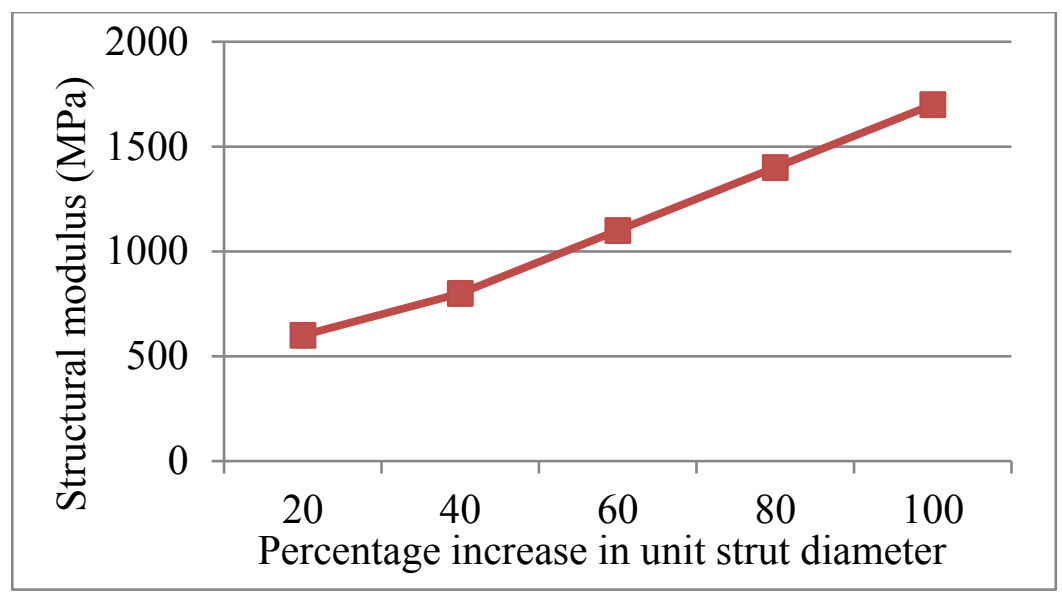

Figure.12.Mechanical response of the scaffold for variation in strut diameter

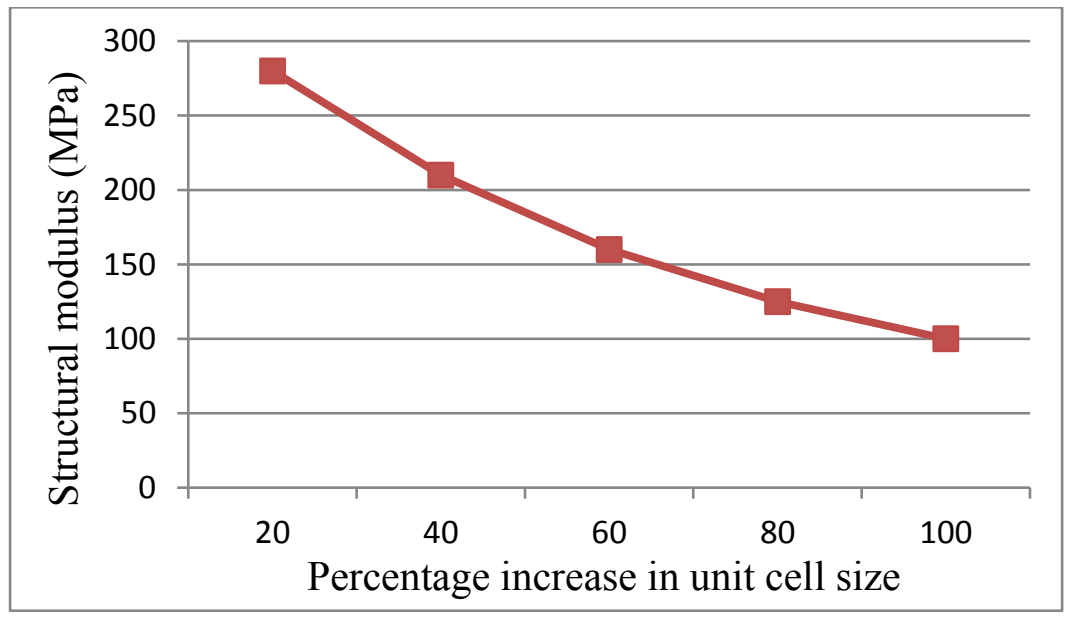

Figure.13.Mechanical response of the scaffold for variation in unit cell size

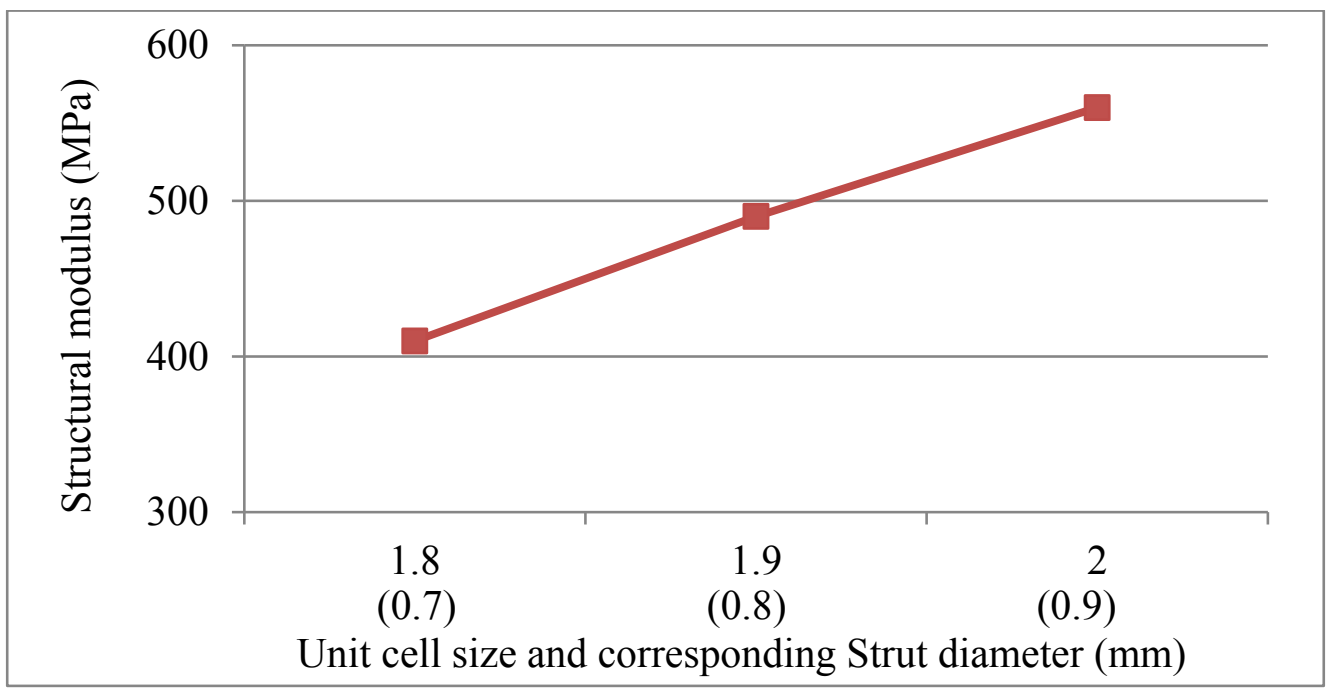

Figure.14. Mechanical response of the scaffold for constant pore size $1.1 \mathrm{~mm}$ 
It is evident from the result that structural modulus increases as the strut diameter increases and decreases as the unit cell size increases. The result shows a steady but nonlinear co-relation between design parameters and the structural modulus. As both unit cell size and the strut diameter increased simultaneously maintaining a constant pore size, structural modulus increased almost linearly. Based on the response of the scaffold structure, parameters were varied to optimize the scaffold. Considering the mechanical integrity, an initial strut diameter of $0.6 \mathrm{~mm}$ was chosen and a pore size of $0.8 \mathrm{~mm}$ was maintained for efficient cell growth [36, 37, 38]. For bone tissues, an ideal scaffold micro-architecture should be highly porous with interconnected pores of defined pore sizes of $200-900 \mu \mathrm{m}$ in diameter in the case of bone [39] and exhibit a high surface area-to-volume ratio [40] to allow high rates of mass transfer [40], cell in-growth and vascularization [41]. This scaffold structure revealed an initial structural modulus of $0.506 \mathrm{GPa}$. In light of the sensitivity analysis it was decided to increase both strut diameter and unit cell size simultaneously by maintaining the pore size at $0.8 \mathrm{~mm}$. The structural modulus increased from $0.506 \mathrm{GPa}$ to $1.155 \mathrm{GPa}$ at the unit cell size of $2.2 \mathrm{~mm}$ and strut diameter of $1.4 \mathrm{~mm}$. The Figure 15 shows the variation of structural modulus.

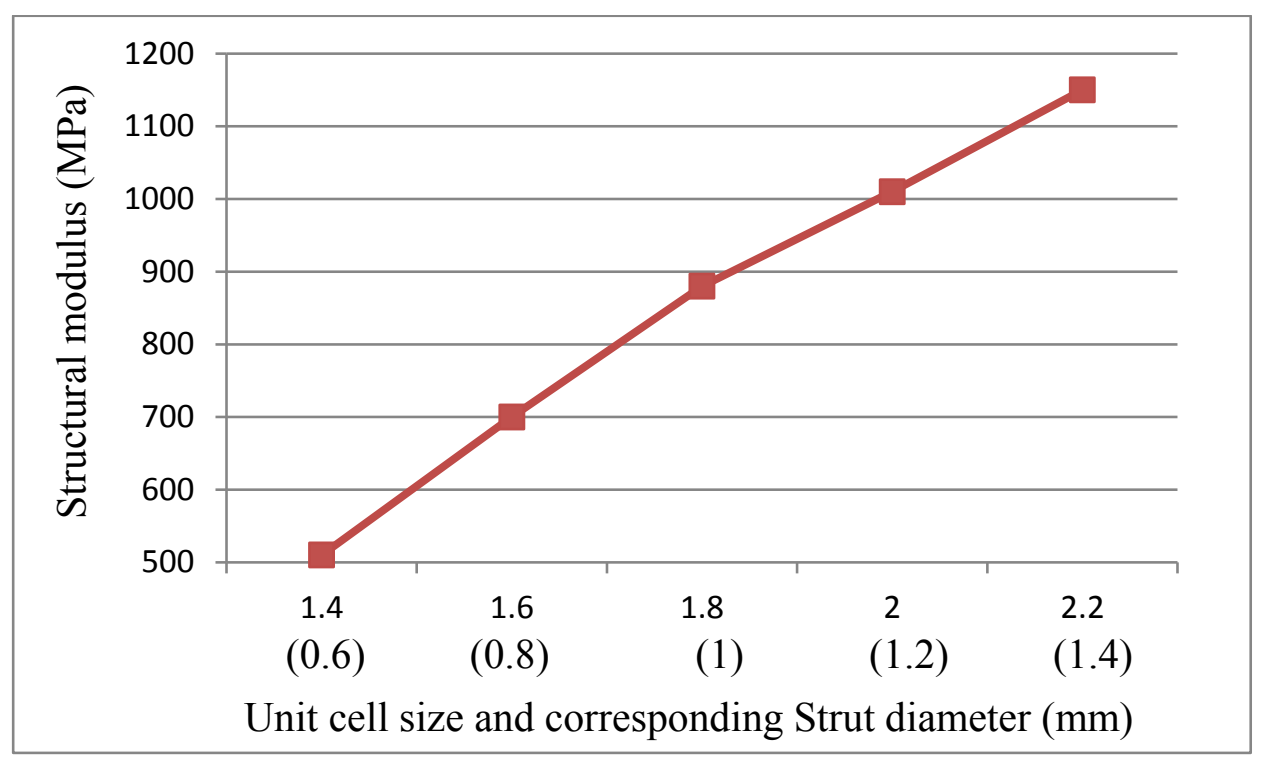

Figure.15. Variation of structural modulus for pore size of $0.8 \mathrm{~mm}$

The unit cell size was further decreased from $2.2 \mathrm{~mm}$ by $0.001 \mathrm{~mm}$ to optimize its structural modulus to $1.15 \mathrm{GPa}$. The optimum value was obtained at the unit cell size of $2.197 \mathrm{~mm}$ and pore size of $0.797 \mathrm{~mm}$. Figure. 16 shows the optimized value of unit cell. 


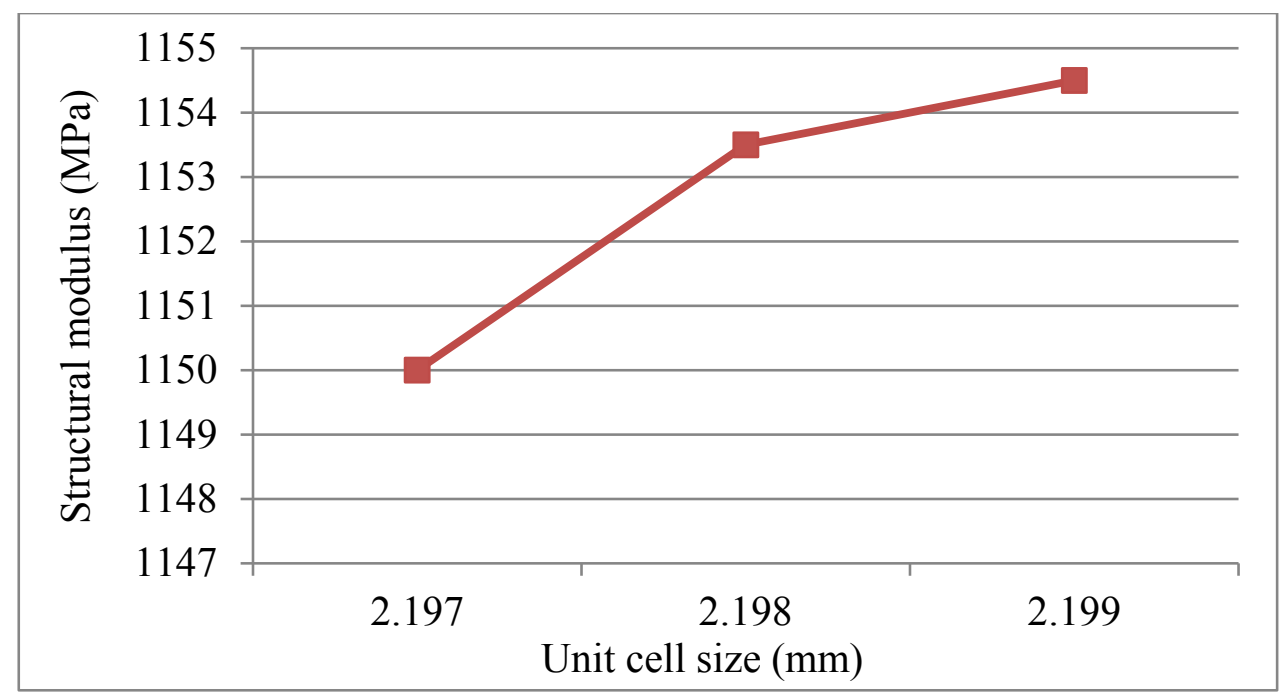

Figure.16. Optimization of unit cell size

Similar procedure was used to optimize other two scaffold structures with square and hexagonal cross section. Table1 shows the optimized values of the scaffold structures.

Table.1.Optimized values of the scaffold structures

\begin{tabular}{|l|l|l|l|}
\hline $\begin{array}{l}\text { Cross } \\
\text { section }\end{array}$ & $\begin{array}{l}\text { Unit cell } \\
\text { size }(\mathrm{mm})\end{array}$ & $\begin{array}{l}\text { Strut } \\
\text { size }(\mathrm{mm})\end{array}$ & $\begin{array}{l}\text { Pore size } \\
(\mathrm{mm})\end{array}$ \\
\hline Circular & 2.197 & 1.4 & 0.797 \\
\hline Square & 1.771 & 1 & 0.771 \\
\hline Hexagonal & 1.975 & 0.953 & 0.814 \\
\hline
\end{tabular}

\subsection{Experimental analysis}

Scaffolds were generated as linear pattern of one structure, having three unit cells in a row and in each spatial direction, thus consisting of 27 unit cells. Length, height and breadth of the scaffold is given by three times the size of the unit cell [42].

The scaffold structures were optimized to $1.15 \mathrm{GPa}$ by varying the design parameters. In order to maintain ASTM standard $(25.4 \mathrm{~mm} \times 25.4 \mathrm{~mm} \times 25.4 \mathrm{~mm})$ unit cell size was fixed at $8.46 \mathrm{~mm}$ and strut diameter was varied to optimize the scaffold structure. Initial strut diameter was chosen as $7.66 \mathrm{~mm}$ and corresponding structural modulus was found to be $2.363 \mathrm{GPa}$. Based on the result from the sensitivity analysis strut diameter was decreased to optimize the scaffold [43]. Figure 17 shows the variation in structural modulus for the decrease in strut diameter. 


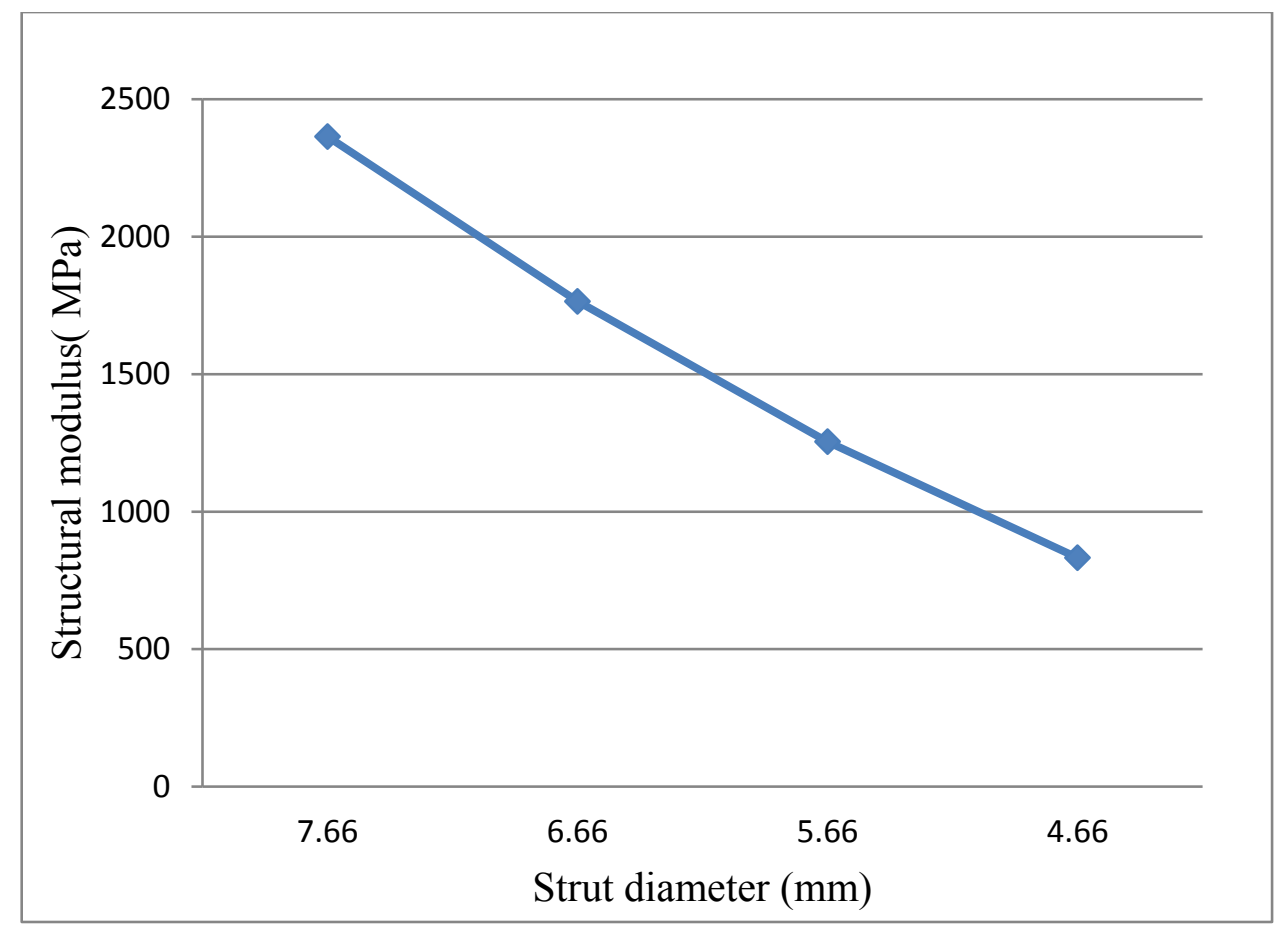

Figure 17 Variation of structural modulus for decrease in strut diameter by $1 \mathrm{~mm}$

From the graph (Figure 17) it was found that structural modulus of the scaffold structure varies from $1.254 \mathrm{GPa}$ to $0.832 \mathrm{GPa}$ for different sizes $5.66 \mathrm{~mm}$ and $4.66 \mathrm{~mm}$. Hence the strut diameter was decreased from $5.66 \mathrm{~mm}$ to get the required structural modulus. Figure 18 shows the convergence of the structural modulus. At the strut diameter of $5.36 \mathrm{~mm}$ the value of the structural modulus was $1.152 \mathrm{GPa}$, which was further optimized to $1.15 \mathrm{GPa}$ by decreasing strut diameter to $5.306 \mathrm{~mm}$.

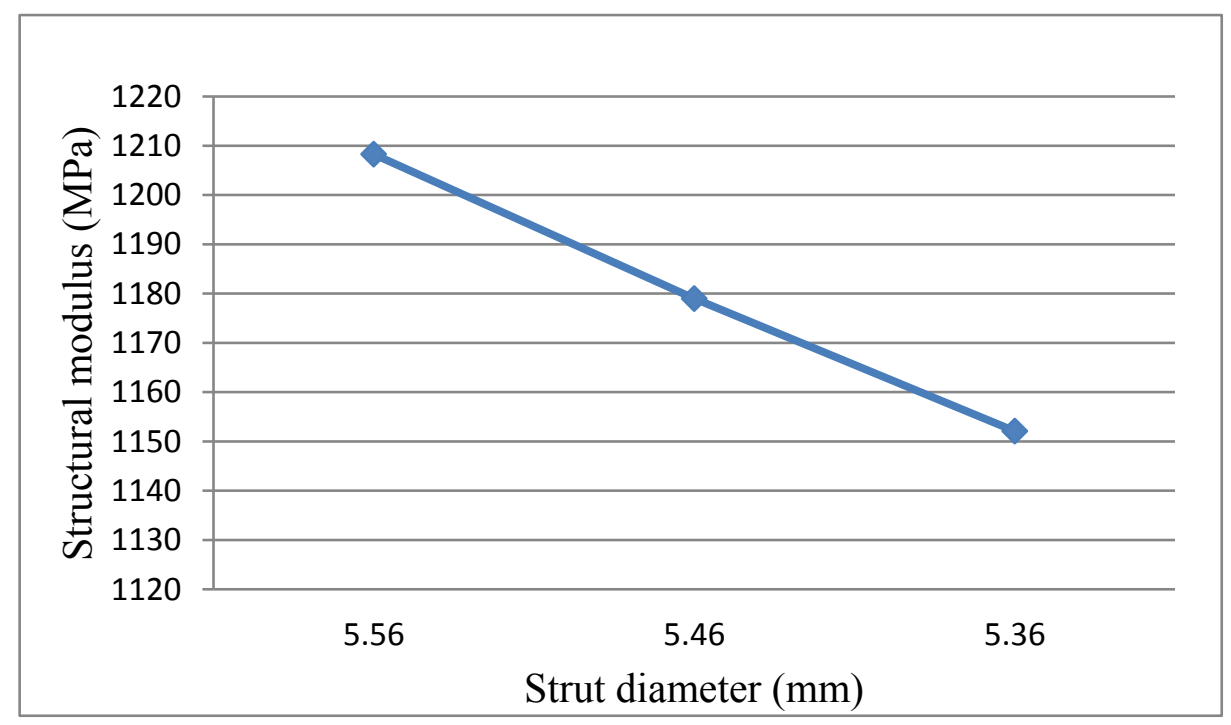

Figure 18 Convergence of structural modulus 
Similar procedures were followed to optimize other two scaffold structures with unit cell having square and hexagonal cross section. Table 2 shows the optimized value of the scaffold structures. The test specimen is revealed in the Figure 19.

Table 2 Optimized value of the polyamide scaffold structures

\begin{tabular}{|c|c|c|}
\hline Cross section & Unit cell size (mm) & Strut diameter (mm) \\
\hline Circular & 8.46 & 5.306 \\
\hline Square & 8.46 & 4.709 \\
\hline Hexagon & 8.46 & 5.982 \\
\hline
\end{tabular}

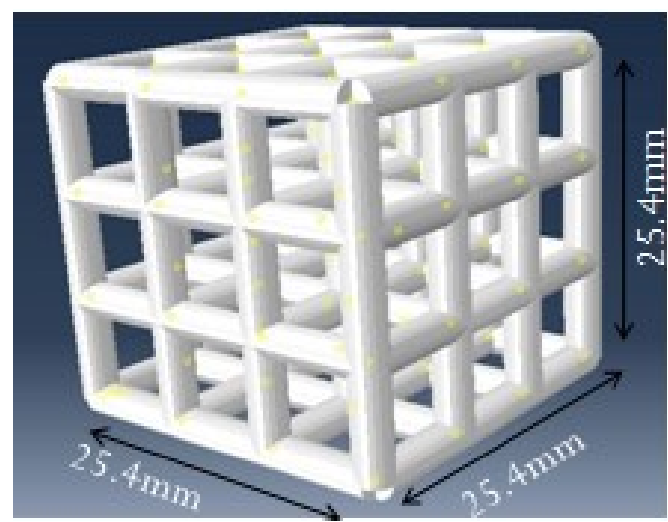

(a)

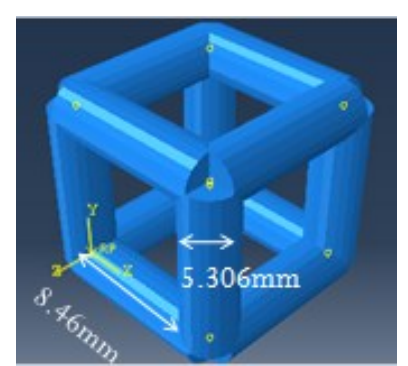

(b)

Figure 19 (a) Specification of scaffold (b) Specification of unit cell

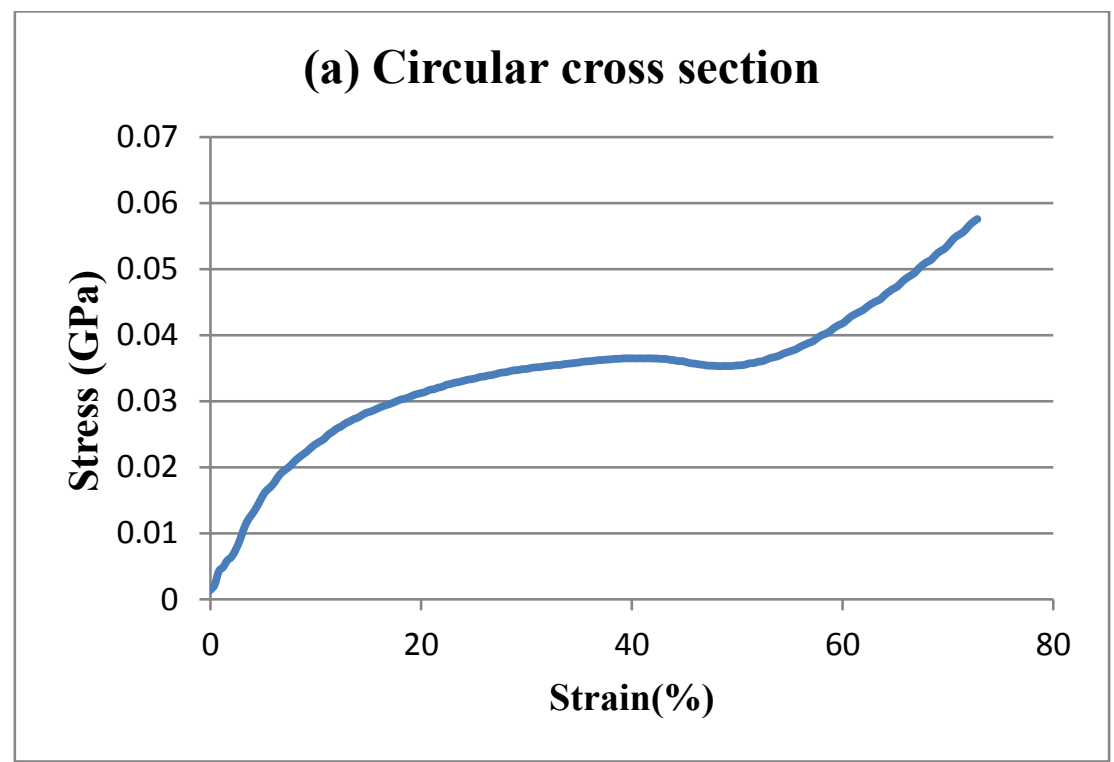



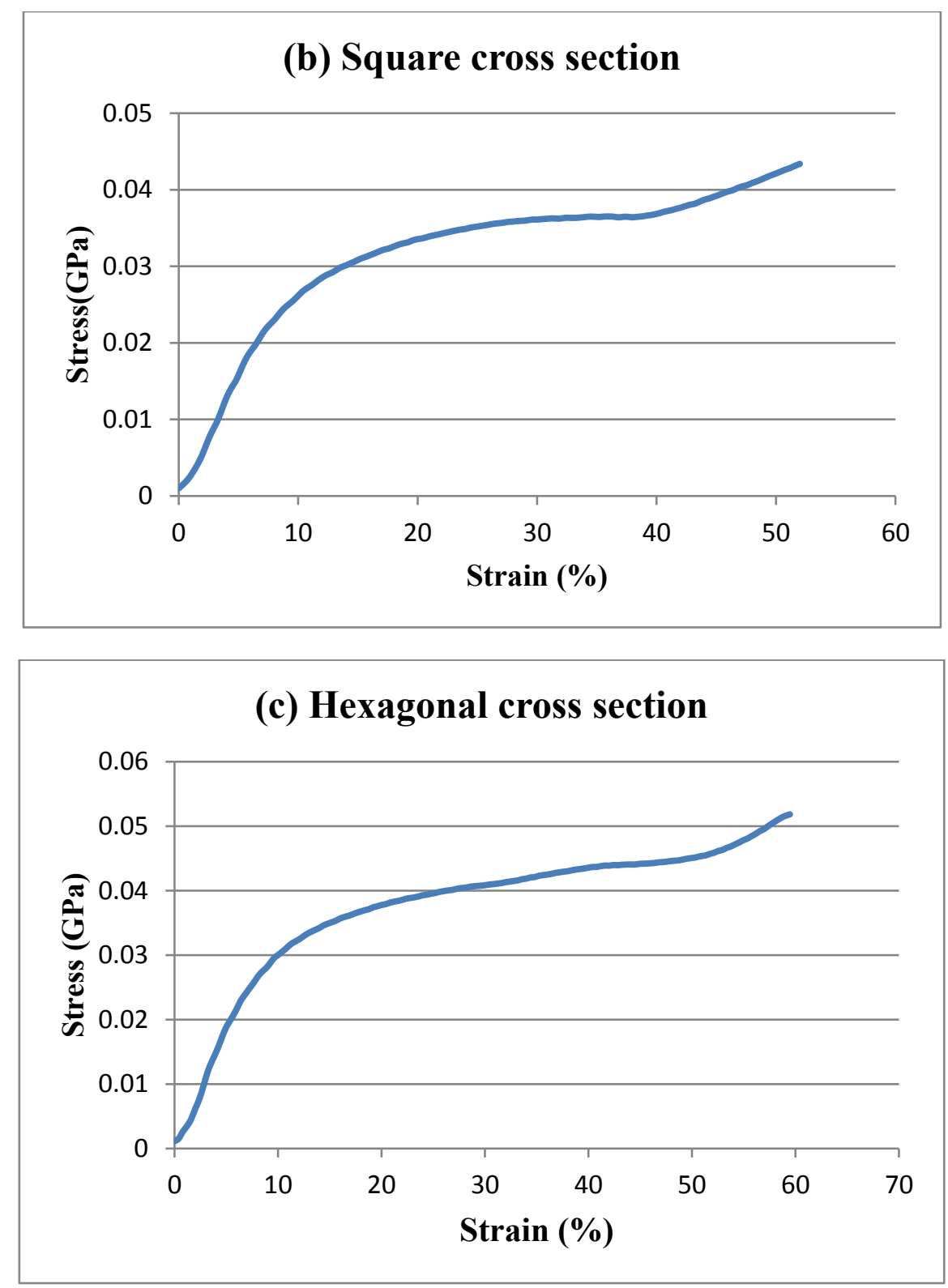

Figure.20. Stress strain relation for (a) Circular cross section (b) Square cross section (c) hexagonal cross section

All three types of scaffold exhibited a linear response for a small region followed by elastic response up to $20 \%$ of strain and yield region extends up to $45 \%$ to $50 \%$ of strain. Figure 20. shows the Stress strain relation for Circular cross section, Square cross section and hexagonal cross section. After yielding, the stress value decreases as the strain value increases to a small extent and starts increasing continuously. This phenomenon was due to the break in horizontal struts at the junction of vertical and horizontal strut. These broken struts join together forming rigid structure account for increase in stress value. The mechanical property of the scaffold was derived from the stress strain relationship. The structural modulus of the scaffold was calculated at the linear region for $10 \%$ of strain. Structural moduli of different cross sections were obtained from experimental test and their corresponding deviations from the optimized value were shown in table 3 . 
Table.3. Deviation of structural modulus

\begin{tabular}{|l|l|l|l|}
\hline $\begin{array}{l}\text { Cross } \\
\text { section }\end{array}$ & $\begin{array}{l}\text { Optimized } \\
\text { value } \\
(\mathrm{GPa})\end{array}$ & $\begin{array}{l}\text { Experimental } \\
\text { value }(\mathrm{GPa})\end{array}$ & $\begin{array}{l}\text { Deviation } \\
(\%)\end{array}$ \\
\hline Circular & 1.15 & 0.989 & 14 \\
\hline Square & 1.15 & 1.03 & 10 \\
\hline Hexagonal & 1.15 & 0.950 & 17 \\
\hline
\end{tabular}

\subsection{In-vitro ANALYSIS}

The number of viable cells in all the well plates after exposure to the scaffold extracts and the respective controls were measured using the MTT assay. The results obtained from MTT assay are presented in Table 4 . The scaffold structure with square cross section has the maximum percentage of cell viability of $58.33 \%$. The increase in cell growth for the three scaffolds indicates that the polyamide customised bone scaffolds were non-toxic to the cells and were able to encourage the growth of cells to proliferate as a monolayer. This study demonstrates that the scaffolds were free from toxicity and biocompatible with cells.

Table 4 Details of Cell Growth in unit cells

\begin{tabular}{|c|c|c|c|c|}
\hline Cross section & Sample 1 & Sample 2 & Average & Cell growth (\%) \\
\hline Circular & 0.107 & 0.116 & 0.111 & 34.26 \\
\hline Hexagonal & 0.116 & 0.124 & 0.120 & 37.03 \\
\hline Square & 0.178 & 0.201 & 0.189 & 58.33 \\
\hline $\begin{array}{c}\text { Cells Without } \\
\text { Scaffold }\end{array}$ & 0.355 & 0.290 & 0.324 & 100 \\
\hline
\end{tabular}

\subsection{CAD tool}

By comparing the Analytical and Experimental result, the unit cell with square cross section was found to be the optimized structure with respect to material and pore size. Then generation of customized bone scaffold was automated by developing a special program in CATIA V5 using the language Visual Basic. And the user form was developed to get the necessary customized input parameters from the user. The special user form developed was shown in Figure 21 and description of unit cell was shown in figure 22. 


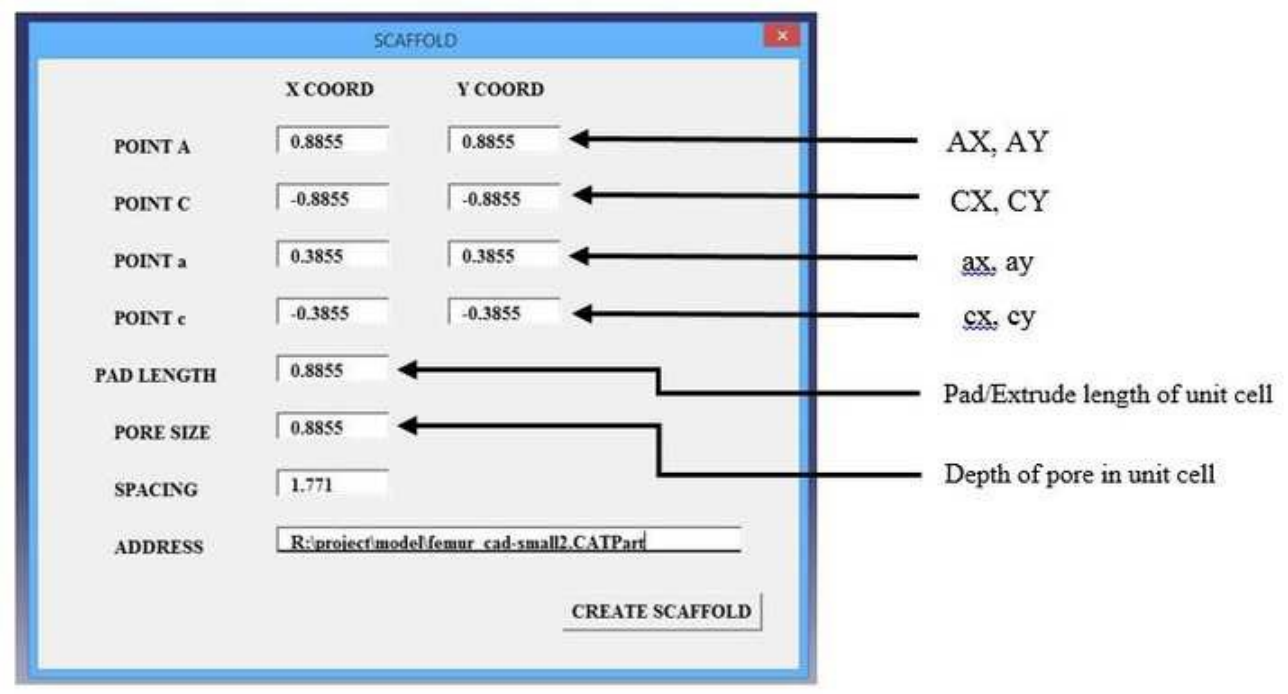

Figure.21.Special user form

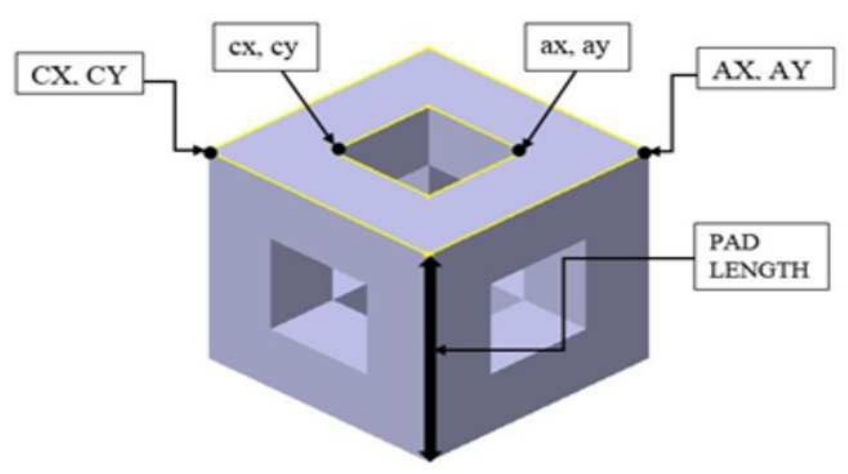

Figure.22. Description of unit cell

From the above user form AX, AY \& CX, CY are the coordinates of the outer square which acts as the wall of the unit cell. Then the coordinates ax, ay \& cx, cy denotes the inner/smaller square which creates the pore in the unit cell. The "SPACING" text box in user form represents the connectivity between the unit cells when they get arranged in orthogonal directions. The "ADDRESS" text box gets the system location address of the bone for which the customized scaffold has to be generated. The unit cell is imported into 3D bone model using Address box and intersected within the 3D bone model. Boolean intersection and subtraction is performed to get the desired structure as shown in Figure 23. By using this automation tool, customized scaffold of the damaged subchondral bone had been generated with optimized dimensions of the unit cell having square cross-section. Figure 23 shows the damaged part of the bone replaced with customized bone scaffold. 


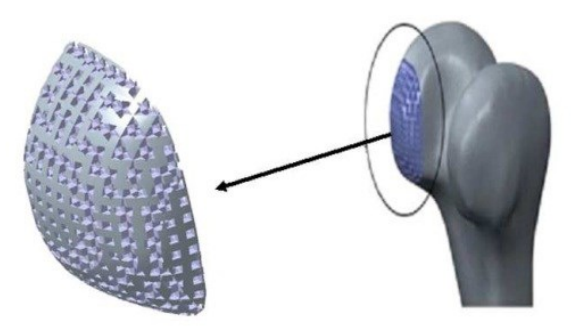

Figure.23.Damaged bone reconstruction with customized bone scaffold

\section{Conclusion}

Experimental investigations were carried out to optimize the structural modulus of scaffold structure to match the elastic property of bone and to auto-generate microstructures (unit block) by means of the newly developed CAD tool, which enabled the micro structures to get integrated piecewise and effortlessly combined into a scaffold structure based on their mechanical function. The following conclusions were drawn from this study:

- The unit cell used to make the scaffold structure was optimized by varying the design parameters to match its structural modulus with Young modulus of human subchondral bone.

- The optimized scaffold structure was fabricated using selective laser sintering method and the structure was validated through uniaxial compression. Experimental test revealed a deviation in structural modulus about $14 \%, 10 \%$ and $17 \%$ for circular, square and hexagonal cross section respectively. Among the three strut cross sections, Square cross section was recommended with respect to reduced unit cell size and optimum pore size.

- The preliminary MTT (Methyl Thiazolyl diphenyl- Tetrazolium bromide) assay tests to evaluate the distributions of cells were performed, using in-vitro perfusion culture experiments. It was found that the scaffold structure with square cross section has the maximum percentage of cell viability of $58.33 \%$.

- A Computer-Aided Design tool has been developed using CATIA V5 Visual Basic program for modelling the bone scaffolds with better interconnectivity of unit blocks, porosity and compressive strength

\section{Compliance with Ethical Standards;}

Conflict of Interest: We declare that there is no any conflict of interest.

Ethical approval: This article does not contain any studies with human participants or animals performed by any of the authors.

\section{References}

1. de Amorim Almeida, H., \& da Silva Bártolo, P. J. (2010). Virtual topological optimisation of scaffolds for rapid prototyping. Medical engineering \& physics, 32(7), 775-782. 
2. Boccaccio, A., Ballini, A., Pappalettere, C., Tullo, D., Cantore, S., \& Desiate, A. (2011). Finite element method (FEM), mechanobiology and biomimetic scaffolds in bone tissue engineering. International journal of biological sciences, 7(1), 112.

3. Cheah, C. M., Chua, C. K., Leong, K. F., Cheong, C. H., \& Naing, M. W. (2004). Automatic algorithm for generating complex polyhedral scaffold structures for tissue engineering. Tissue Engineering, 10(3-4), 595-610.

4. Lin, C. Y., Kikuchi, N., \& Hollister, S. J. (2004). A novel method for biomaterial scaffold internal architecture design to match bone elastic properties with desired porosity. Journal of biomechanics, 37(5), 623-636.

5. Cheah, C. M., Chua, C. K., Leong, K. F., \& Chua, S. W. (2003). Development of a tissue engineering scaffold structure library for rapid prototyping. Part 1: investigation and classification. The International Journal of Advanced Manufacturing Technology, 21(4), 291-301.

6. Hutmacher, D. W. (2001). Scaffold design and fabrication technologies for engineering tissues - state of the art and future perspectives. Journal of Biomaterials Science, Polymer Edition, 12(1), 107-124.

7. Holy, C. E., Shoichet, M. S., \& Davies, J. E. (2000). Engineering three- dimensional bone tissue in vitro using biodegradable scaffolds: Investigating initial cell- seeding density and culture period. Journal of Biomedical Materials Research, 51(3), 376-382.

8. Huiskes, R., Weinans, H., \& Van Rietbergen, B. (1992). The relationship between stress shielding and bone resorption around total hip stems and the effects of flexible materials. Clinical orthopaedics and related research, 124-134.

9. Itälä, A. I., Ylänen, H. O., Ekholm, C., Karlsson, K. H., \& Aro, H. T. (2001). Pore diameter of more than $100 \mu \mathrm{m}$ is not requisite for bone ingrowth in rabbits. Journal of Biomedical Materials Research, 58(6), 679-683.

10. Yang, S., Leong, K. F., Du, Z., \& Chua, C. K. (2001). The design of scaffolds for use in tissue engineering. Part I. Traditional factors. Tissue engineering, 7(6), 679-689.

11. Choi, K., Kuhn, J. L., Ciarelli, M. J., \& Goldstein, S. A. (1990). The elastic moduli of human subchondral, trabecular, and cortical bone tissue and the size-dependency of cortical bone modulus. Journal of biomechanics, 23(11), 1103-1113.

12. Leong, K. F., Cheah, C. M., \& Chua, C. K. (2003). Solid freeform fabrication of three-dimensional scaffolds for engineering replacement tissues and organs. Biomaterials, 24(13), 2363-2378.

13. Li, J. P., Habibovic, P., van den Doel, M., Wilson, C. E., de Wijn, J. R., van Blitterswijk, C. A., \& de Groot, K. (2007). Bone ingrowth in porous titanium implants produced by 3D fiber deposition. Biomaterials, 28(18), 2810-2820.

14. Begum, S. R., \& Arumaikkannu, G. (2015). Computational fluid dynamic analysis and additive manufacturing of customised bone scaffolds. Progress in Computational Fluid Dynamics, an International Journal, 15(3), 197-201.

15. Lopez- Heredia, M. A., Goyenvalle, E., Aguado, E., Pilet, P., Leroux, C., Dorget, M., Weiss P., \& Layrolle, P. (2008). Bone growth in rapid prototyped porous titanium implants. Journal of Biomedical Materials Research Part A, 85(3), 664-673.

16. Luxner, M. H., Stampfl, J., \& Pettermann, H. E. (2005). Finite element modeling concepts and linear analyses of 3D regular open cell structures. Journal of Materials science, 40(22), 5859-5866.

17. Vandenbroucke, B \& Kruth, JP (2007), Selective laser melting of biocompatible metals for rapid manufacturing of medical parts, Rapid prototyping journal, vol.13, no.4, pp.196-203. 
18. Dias, M. R., Guedes, J. M., Flanagan, C. L., Hollister, S. J., \& Fernandes, P. R. (2014). Optimization of scaffold design for bone tissue engineering: a computational and experimental study. Medical engineering \& physics, 36(4), 448-457.

19. Zhao, D., Zhu, T., Li, J., Cui, L., Zhang, Z., Zhuang, X., \& Ding, J. (2020). Poly (lactic-co-glycolic acid)-based composite bone-substitute materials. Bioactive Materials, 6(2), 346-360.

20. Cui, L., Zhang, J., Zou, J., Yang, X., Guo, H., Tian, H., Zhang, P., Wang, Y., Zhang, N., Zhuang, X. \& Li, Z. (2020). Electroactive composite scaffold with locally expressed osteoinductive factor for synergistic bone repair upon electrical stimulation. Biomaterials, 230, 119617.

21. Shuai, C., Yang, W., Feng, P., Peng, S., \& Pan, H. (2020). Accelerated degradation of HAP/PLLA bone scaffold by PGA blending facilitates bioactivity and osteoconductivity. Bioactive Materials, 6(2), 490-502.

22. Shuai, C., Yu, L., Feng, P., Zhong, Y., Zhao, Z., Chen, Z., \& Yang, W. (2020). Organic montmorillonite produced an interlayer locking effect in a polymer scaffold to enhance interfacial bonding. Materials Chemistry Frontiers, 4(8), 2398-2408.

23. Zhu, T., Cui, Y., Zhang, M., Zhao, D., Liu, G., \& Ding, J. (2020). Engineered threedimensional scaffolds for enhanced bone regeneration in osteonecrosis. Bioactive Materials, 5(3):584-601.

24. Sudarmadji, N., Tan, J. Y., Leong, K. F., Chua, C. K., \& Loh, Y. T. (2011). Investigation of the mechanical properties and porosity relationships in selective laser-sintered polyhedral for functionally graded scaffolds. Acta biomaterialia, 7(2), 530-537.

25. Olivares, A. L., Marsal, È., Planell, J. A., \& Lacroix, D. (2009). Finite element study of scaffold architecture design and culture conditions for tissue engineering. Biomaterials, 30(30), 6142-6149.

26. Parthasarathy, J., Starly, B., Raman, S., \& Christensen, A. (2010). Mechanical evaluation of porous titanium (Ti6Al4V) structures with electron beam melting (EBM). Journal of the mechanical behavior of biomedical materials, 3(3), 249-259.

27. Ponader, S., Von Wilmowsky, C., Widenmayer, M., Lutz, R., Heinl, P., Körner, C., ... \& Schlegel, K. A. (2010). In vivo performance of selective electron beam- melted Ti- 6Al- 4V structures. Journal of Biomedical Materials Research Part A, 92(1), 5662.

28. Rashia Begum, S., \& Arumaikkannu, G. (2013). Design, analysis and fabrication of customised bone scaffold using RP technology. International journal of computer applications in technology, 47(4), 364-369.

29. Langer R., Vacanti J. P. (1993) Tissue engineering; Science, 260, 920-926.

30. Serra, T., Planell, J. A., \& Navarro, M. (2013). High-resolution PLA-based composite scaffolds via 3-D printing technology. Acta biomaterialia, 9(3), 5521-5530.

31. Saito, E., Liu, Y., Migneco, F., \& Hollister, S. J. (2012). Strut size and surface area effects on long-term in vivo degradation in computer designed poly (l-lactic acid) three-dimensional porous scaffolds. Acta biomaterialia, 8(7), 2568-2577.

32. Sudarmadji, N., Tan, J. Y., Leong, K. F., Chua, C. K., \& Loh, Y. T. (2011). Investigation of the mechanical properties and porosity relationships in selective laser-sintered polyhedral for functionally graded scaffolds. Acta biomaterialia, 7(2), 530-537. 
33. Szymczyk, P., Łabowska, M. B., Detyna, J., Michalak, I., \& Gruber, P. (2020). A review of fabrication polymer scaffolds for biomedical applications using additive manufacturing techniques. Biocybernetics and Biomedical Engineering, 40(2): 624638.

34. Murr, L. E. (2020). Metallurgy principles applied to powder bed fusion 3D printing/additive manufacturing of personalized and optimized metal and alloy biomedical implants: an overview. Journal of Materials Research and Technology, 9(1), 1087-1103.

35. Javaid, M., \& Haleem, A. (2018). Additive manufacturing applications in medical cases: A literature based review. Alexandria Journal of Medicine, 54(4), 411-422.

36. Yuan, L., Ding, S., \& Wen, C. (2019). Additive manufacturing technology for porous metal implant applications and triple minimal surface structures: A review. Bioactive Materials, 4, 56-70.

37. Shuai, C., Cheng, Y., Yang, Y., Peng, S., Yang, W., \& Qi, F. (2019). Laser additive manufacturing of $\mathrm{Zn}-2 \mathrm{Al}$ part for bone repair: Formability, microstructure and properties. Journal of Alloys and Compounds, 798, 606-615.

38. Singh, S., Ramakrishna, S., \& Singh, R. (2017). Material issues in additive manufacturing: A review. Journal of Manufacturing Processes, 25, 185-200.

39. Chu, T. M., Halloran, J. W., Hollister, S. J., \& Feinberg, S. E. (2001). Hydroxyapatite implants with designed internal architecture. Journal of Materials Science: Materials in Medicine, 12(6), 471-478.

40. Shieh, M. (2000). Control of bone cell functions on three-dimensional tissue engineering scaffolds. BUG J, 3, 194-204.

41. Borden, M., Attawia, M., Khan, Y., \& Laurencin, C. T. (2002). Tissue engineered microsphere-based matrices for bone repair:: design and evaluation. Biomaterials, 23(2), 551-559.

42. Lipowiecki, M., \& Brabazon, D. (2010). Design of bone scaffolds structures for rapid prototyping with increased strength and osteoconductivity. In Advanced Materials Research, Vol. 83, pp. 914-922.

43. Kumar, P., Saini, M., Dehiya, B. S., Sindhu, A., Kumar, V., Kumar, R., ... \& Thakur, R. (2020). Comprehensive survey on nanobiomaterials for bone tissue engineering applications. Nanomaterials, 10(10), 2019. 